\title{
Recycling of Demolished Concrete and Mortar in Manufacturing of Aggregate
}

\author{
Ramesh Balu Ranpise ${ }^{1}$, M. S. Salunkhe ${ }^{2}$ \\ Department of Environmental Science and Technology, Department of Technology (DOT), Kolhapur, India
}

\begin{abstract}
Kolhapur is presently generating construction and demolition waste to the tune of aprox.900 tons annually and these figures are likely to double fold in the next 2 years. Concrete has been seen as a resource in developed countries. Works on recycling have emphasized that if old concrete has to be used in second generation concrete, the product should adhere to the required compressive strength. Literature survey reveals that compressive strength primarily depends upon adhered mortar, water absorption, Los Angeles abrasion, size of aggregates, strength of parent concrete, age of curing and ratio of replacement, interfacial transition zone, moisture state, impurities present and controlled environmental condition. Some of the studies have suggested the mix design procedure for recycled aggregates in concrete, yet a simple and Environment effective method of using demolished concrete, taking into account \% adhered mortar and thus calculating mix composition needs to be developed. This project deals with the review of the existing literature work for the use of recycled concrete as aggregates in concrete in respect of mainly the compressive strength and proposes an approach for use of recycled concrete aggregate without compromising the strength.
\end{abstract}

Keywords: Construction and demolished concrete, Second generation concrete, Adhere, recycling, workability, recycle aggregate, compressive strength

\section{Introduction}

Kolhapur Construction industry growth is substantial in size.Predicts an increase in construction spending from of $48 \%$ in year2015. These figures indicate a tremendous growth in the construction sector and could be almost one and a half times in the coming 5 years. Concrete is the premier construction material across the world and the most widely used in all types of civil engineering works, including infrastructure, low and high-rise buildings, defence installations ,environment protection and local/domestic developments. Concrete is a manufactured product, essentially consisting of cement, aggregates, water and admixture. Among these, aggregates.

Until quite recently, and despite years of experience in the field, the construction industry has seemed quite oblivious to worries about managing the waste produced. Construction is not only one of greatest generators of waste; it also consumes around $40 \%$ of all extracted natural resources. It is thus essential to intervene to encourage more sustainable construction practices. Studies on the use of recycled aggregates have mostly focused on their coarse fraction and ignored the fine fraction. This is basically because the extreme porosity of fine recycled materials leads to reductions in the performance of any composites containing them. The most important characteristics of hardened mortar for wall covering are: mechanical strength, water permeability, adhesive strength and resistance to weathering, and those of fresh mortar are workability, and water retentively. Several mortars with recycled aggregates are assessed based on these characteristics and by comparison with a reference conventional mortar, in order to verify their performance as renderings.(CatarinaNeno' Jorge de Brito ,RosárioVeiga)In fact many governments throughout the world have now introduced various measures aimed at reducing the use of primary aggregates and increasing reuse and recycling, where it is technically, economically, or environmentally acceptable.

\section{Motivation}

To reduce environmental hazards-Concrete is the most widely used construction material in the world, with demand being continually driven through the growth of emerging economies. In fact, concrete is so widely used that global cement and aggregates production contributes about $5 \%$ to annual greenhouse gas emissions, a level comparable to the aviation sector. Greenhouse gases released into the atmosphere, such as carbon dioxide, significantly affect the Earth's temperature. Concrete production can also contribute to a progressive depletion of natural resources, resulting in serious environmental damage if left unchecked. Recycling of aggregates was first carried out after II World war in Germany to tackle the problem of disposing large amount of demolition waste caused by the war and simultaneously generate raw material for reconstruction. Recycling of aggregate material from construction and demolition waste may reduce the demand supply gap in this sector. Apart from mounting problems of waste management, other reasons which support adoption of recycling strategy arereduced extraction of raw materials, reduced transportation cost and reduced environmental impact because during their excavation manufacturing, transportation tremendous amount of dust particles are produced.

\section{Need to use RCA}

Waste arising from Construction and Demolition constitutes one of the largest waste streams within the EU, Asian and many other countries. For example, it is estimated that core waste (described as those types of materials which are obtained from demolished building or civil engineering infrastructure) amounts to around $520 \mathrm{~kg} /$ person/yr in India. This ranges from over $700 \mathrm{~kg} /$ person/yr in Germany and the Netherlands to under 200 in Sweden, Greece and Ireland.This is in addition to large quantities that are dumped illegally. Thus, construction demolition waste has become a global concern that requires sustainable solution. 


\section{International Journal of Science and Research (IJSR) \\ ISSN (Online): 2319-7064 \\ Index Copernicus Value (2013): 6.14 | Impact Factor (2013): 4.438}

It is now widely accepted that there is a significant potential for reclaiming and recycling demolished debris for use in value added applications to maximize economic and environmental benefits As a direct result of this, recycling industries in many part of the world, including South Africa, at present converts low-value waste into secondary construction materials such as a variety of aggregate grades, road materials and aggregate fines. Often these materials are used in as road construction, backfill for retaining walls, low grade concrete production, drainage and brickwork and block work for low-cost housing. While accepting the need to promote the use of RCA in wider applications, it must be remembered that the aggregate for concrete applications must meet the requirements set in relevant specifications for its particular use. The gap between these interests has to be reduced in steps that are manageable and the use of RCA in structural concrete has to be promoted gradually. Similarly considerable attention is required to the control of waste processing and subsequent sorting, crushing, separating and grading the aggregate for use of the concrete construction industry. In some developed countries C \& D waste is now regularly recycled and reused, albeit mainly as fill, drainage and sub-base materials, and there is considerable scope for increasing this market and the use of these materials.

In addition, there is an urgent need for legislative or regulatory measures to implement sustainable $\mathrm{C} \& \mathrm{D}$ waste management strategy and encourage recycling for use in value added applications.

\section{Scope}

The scope of this pilot project is based on the replacement of conventional coarse aggregate $(100 \%)$ with recycled concrete aggregate. The reason for using only coarse aggregates in recycling is that the fine aggregate replacement in terms of concrete dust increases the water demand of concrete which results in decrease of strength. Due to the presence of cement powder around the recycled aggregates, the water requirement for desired workability increases.

\section{Material and Methodology}

The recycled aggregates were obtained from local sight at Tarabai park Kop-3 from an water tanks demolishe waste .It was ensured that the specimens collected was free from any supplementary cementitious material or chemical admixture.

\section{Tests on Recycled Aggregate}

Demolished material of reinforced cement concrete (RCC) \& PCC is used for recycling in foundation. The life of RCC demolish material is $25 \mathrm{yrs}$. Such mated crushing, sieving \& separation process are done by manual crushing method. On demolish material, aggregate tests are conducted which are mentioned in Indian Standard code for natural aggregate \& check feasibility.

\section{Properties of Recycled Concrete Aggregate}

Particle SizeDistribution:-Sieve analysis is carried out as per IS 2386 for crushed recycled concrete aggregate and natural aggregates. It is found that recycled coarse aggregate are reduced to various sizes during the process of crushing and sieving, which gives the best particle size distribution. The amounts of fine particles less than $4.75 \mathrm{~mm}$ after recycling of demolished waste were in the order of 5-20\% depending upon the original grade of demolished concrete. The best quality natural aggregate can be obtained by primary, secondary \& tertiary crushing, whereas the same can be obtained after primary \& secondary crushing incase of recycled aggregate. The single crushing process is also effective in the case of recycled aggregate. The particle shape analysis of recycled aggregate indicates similar particle shape of natural aggregate obtained from crushed rock. The recycled aggregate generally meets all the standard requirements of aggregate used in concrete.

Specific Gravity:-The specific gravity in saturated surface dry condition of recycled concrete aggregate was found from 2.35 to 2.58 which are less but satisfying the results. If specific gravity is less than 2.4 , it may cause segregation, honeycombing $\&$ also yield of concrete may get reduced.

Water Absorption:-The RCA from demolished concrete consist of crushed stone aggregate with old mortar adhering to it, the water absorption ranges from $1.5 \%$ to $7.0 \%$, which is relatively higher than that of the natural aggregates. Thus the water absorption results are satisfactory.

Bulk Density The bulk density of recycled aggregate is lower than that of natural aggregate, thus results are not satisfactory; due to less Bulk Density the mix proportion gets affected.

Crushing and Impact Values The recycled aggregate is relatively weaker than the natural aggregate against different mechanical actions. As per IS 2386 part (IV), the crushing and impact values for concrete wearing surfaces should not exceed $30 \% \&$ for other than wearing surfaces $45 \%$ respectively. The crushing \& impact values of recycled aggregate satisfy the BIS specifications limit. From crushing \& impact test it is found that use of recycled aggregate is possible for application other than wearing surfaces.

\section{Compressive test on cubes}

The average compressive strengths of cubes cast are determined as per IS 516 using RCA and natural aggregate at the age 3, 7, \& 28days and reported. As expected, the compressive strength of RAC is slightly lower than the conventional concrete made from similar mix proportions. The reduction in strength of RAC as compare to NAC replaced $30 \% 70 \%$ and $100 \%$ for M-20 \& M-25 concretes respectively. The amount of reduction in strength depends on parameters such as grade of demolished concrete, replacement ratio, w/c ratio, processing of recycled aggregate etc. As per test results the strength of recycled aggregate cube is more than target strength, so RCA can be used for construction purpose.

\section{Results and Tables}

The results obtained from the investigation carried out forstructural and non-structural properties on trial basis are as follows 


\section{International Journal of Science and Research (IJSR) \\ ISSN (Online): 2319-7064 \\ Index Copernicus Value (2013): 6.14 | Impact Factor (2013): 4.438}

Non structural properties

The physical properties of gravels and recycled aggregates are furnished

\begin{tabular}{|c|c|c|c|}
\hline Sr No. & Properties & $\begin{array}{c}\text { Recycled } \\
\text { Aggregate\% }\end{array}$ & $\begin{array}{c}\text { Natural } \\
\text { Aggregate\% }\end{array}$ \\
\hline 1 & Water Absorption & $7.2 \%$ & $1 \%$ \\
\hline 2 & Specific Gravity & 2.128 & 2.72 \\
\hline 3 & Abrasion Value & $8.2 \%$ & $5.5 \%$ \\
\hline 4 & Attrition Value & $8.2 \%$ & $8.6 \%$ \\
\hline 5 & Impact Value & $26.4 \%$ & $12.5 \%$ \\
\hline
\end{tabular}

Mix Design Proportion Used

M20-1:1.62:3.4

M25-1:2.06:3.87

\section{Structural properties}

The hardened concrete properties were tested in the laboratory and are furnished in table .

Compressive strength

M20

For $3^{\text {rd }}$ Days

\begin{tabular}{|l|l|l|}
\hline. & Replacement $\%$ & Strength N/mm2 \\
\hline 1 & 0 & 18.48 \\
\hline 2 & 30 & 20.28 \\
\hline 3 & 70 & 20.64 \\
\hline 4 & 100 & 23.84 \\
\hline
\end{tabular}

For $7^{\text {th }}$ Days

\begin{tabular}{|l|l|l|}
\hline & Replacement $\%$ & Strength N/mm2 \\
\hline 1 & 0 & 27.28 \\
\hline 2 & 30 & 23.93 \\
\hline 3 & 70 & 22.35 \\
\hline 4 & 100 & 27.28 \\
\hline
\end{tabular}

M25

$3^{\text {rd }}$ Day

\begin{tabular}{|l|l|l|}
\hline$\cdot$ & Replacement $\%$ & Strength N/mm2 \\
\hline 1 & 0 & 16.13 \\
\hline 2 & 30 & 17.33 \\
\hline 3 & 70 & 17.20 \\
\hline 4 & 100 & 12.19 \\
\hline
\end{tabular}

$7^{\text {th }}$ Day

\begin{tabular}{|l|l|l|}
\hline$\cdot$ & Replacement\% & Strength N/mm2 \\
\hline 1 & 0 & 18.2 \\
\hline 2 & 30 & 22.71 \\
\hline 3 & 70 & 21.44 \\
\hline 4 & 100 & 14.23 \\
\hline
\end{tabular}

Approximate cost of project $30,000 ₹$

\section{Conclusion}

From the experimental work carried out on "Recycle of Concrete Aggregates", the following conclusion can be drawn:

1) The water content used in all mixes is 0.5 .

2) The slump of the normal concrete is observed to be less than the recycled one.

3) The compressive strength of concrete containing $50 \%$ RCA has strength in close proximity to that of normal concrete.
4) Tensile splitting test shows that concrete has goodtensile strength when replace upto $25-50 \%$.

5) The strength of concrete is high during initial stages but gradually reduces during later stages.

6) Water absorption of RCA is higher than natural aggregate.

7) Due to lack of treatment process for RCA adequate strength is not achieved but by applying more advanced and sophisticated treatment process the strength can be improved.

Thus the usage of RCA in concrete mixture is found to havestrength in close proximity to that of natural aggregate and can be used effectively as a full value component of new concrete.

\section{References}

[1] R. Sri Ravindrarajah, "Utilization of Waste Concrete for New Construction", Conwrvorion\&Recycling, Vol. 10.No. 213. pp. 69-74. 1987. 0361-3658187.

[2] Ayed Ahmad Zuhud, "The Performance of Recycled Aggregate Concrete", Thesis, Master ofDesign and Rehabilitation of concrete Structures, Islamic University of Gaza Faculty of Engineering.

[3] Young, P.C ,Teo, D.C.L., “ The Utilization of Recycled aggregate as coarse aggregate in concrete". Unimas EJournal of Civil Engineering, Vol.1, Issue1, August 2009.

[4] R. Kamala, B. Krishna Rao "Reuse of Solid Waste from Building Demolition for the Replacement of Natural Aggregates" International Journal of Engineering and Advanced Technology (IJEAT) ISSN: 2249

[5] A.N.Dabhade, Dr.S.R.Choudhari, Dr.A.R.Gajbhiye "Performance Evaluation Of RecycledAggregate Used In Concrete" International Journal of Engineering Research and Applications ISSN: 2248-9622 www.ijera.com Vol. 2, Issue 4, July-August 2012, pp.1387-1391

[6] HasanTaherkhani,BehnamAmani, " An investigation on the use of recycled concrete and brick in pavement layers" Assistant professor, civil engineering department, University of Zanjan, Zanjan, Iran, ISSN : 0976-2876. 